\title{
The possible role of molecular mimicry in SARS-CoV-2-mediated autoimmunity: an immunobiochemical basis
}

\section{Dženan Kovačić \\ Department of Genetics and Bioengineering, Faculty of Engineering and Natural Sciences, International Burch University, Sarajevo, Bosnia and Herzegovina \\ (iD) https://orcid.org/0000-0003-3218-5073}

Corresponding author: dzenan.kovacic@stu.ibu.edu.ba

\section{Jovana Jotanović}

Faculty of Natural Sciences and Mathematics Department of Biology, Faculty of Science, University of Sarajevo, Bosnia and Herzegovina

(iD) -

\section{Jasmina Laković}

Department of Genetics and Bioengineering, Faculty of Engineering and Natural Sciences, International Burch University, Sarajevo, Bosnia and Herzegovina (iD) -

DOI: https://doi.org/10.20883/medical.e560
Keywords: autoimmunity and COVID19, molecular mimicry and COVID19, SARS-CoV-2 autoimmunity, molecular mimicry

Published: 2021-10-10

How to Cite: Kovačić D, Jotanović J, Laković J. The The possible role of molecular mimicry in SARS-CoV-2-mediated autoimmunity: an immunobiochemical basis. Journal of Medical Science. 2021 Oct. 10;90(3):e560. doi:10.20883/ medical.e560

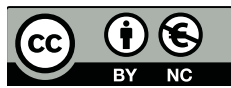

(C) 2021 by the author(s). This is an open access article distributed under the terms and conditions of the Creative Commons Attribution (CC BY-NC) licencse. Published by Poznan University of Medical Sciences

\begin{abstract}
Coronavirus Disease 2019 (COVID-19), caused by the novel Severe Acute Respiratory Syndrome Coronavirus-2 (SARS-CoV-2), persists as a threat to global health and continues to be a rapidly evolving condition. Although COVID19 is negatively correlated with the existing comorbidities in terms of the clinical outcome, the ability of SARS-CoV-2 to mediate the novel, or to exacerbate the existing autoimmune conditions, has generated considerable interest, due to its potential implications both with regard to patients suffering from autoimmune conditions, as well as to the long-term consequences of the disease. However, although molecular mimicry has been postulated as a potential causative factor in post-COVID19 autoimmunity and multiorgan damage, a substantial body of research needs to emerge in order to achieve a more definitive conclusion. We investigated the possibility of SARS-CoV-2 peptide sequences behaving as molecular mimics with a potential to trigger an autoimmune response. Thus, on the basis of analysis in silico, we were able to develop a plausible case for the molecular mimicry as a potential aetiological mechanism of SARS-CoV-2-mediated autoimmunity, both in a multi-organ damage context or outside of the viral phase of infection. Interestingly, this is the first time that the peptide sequence of MACROD1 has been implicated in the COVID-19 autoimmunity. Additionally, we also confirm that PARP9 and PARP14 may be involved in the process.
\end{abstract}

\section{Introduction}

Coronavirus Disease (COVID-19) Pandemic, resulting from by the novel Severe Acute Respi- ratory Syndrome Coronavirus-2 (SARS-CoV-2), persists as a threat to global health and continues to be a rapidly developing situation [1]. Due to the potential implications both with regard to 
patients suffering from autoimmune conditions, as well as to the long-term consequences of COVID-19, COVID-19 has generated considerable attention, although it has been negatively correlated with the existing comorbidities in terms of the clinical outcome, the ability of SARS-CoV-2 to mediate the novel, or to exacerbate the existing autoimmune conditions [2-4]. In spite of the respiratory involvement, as the most prominent symptom, the prospect of the virus triggering the novel autoimmune conditions, or exacerbating the existing ones, is becoming increasingly substantiated by a growing body of research [5-8]. It has been established that, depending on the disease severity, COVID-19 is characterised by cytokine dysregulation, which results in a tissue-damaging cytokine storm in the critically ill patients [5, 9-12]. Single cell RNA sequencing revealed that proinflammatory cytokines are predominantly secreted by monocyte-derived inflammatory macrophages [13]. This causes the onset of acute respiratory distress syndrome (ARDS), with interleukin (IL)-6, IL-1 $\beta$ and tumour necrosis factor (TNF)-a closely correlated with severe ARDS cases, accompanied by multi-organ damage [1, $6,14-16]$. Considering that IL- 6 and IL-1 $\beta$ strongly mediate the recruitment of neutrophils and T cells, it is not at all surprising that these cytokines have been particularly strongly correlated with a severe immunopathology [17-19]. In fact, most COVID-19 patients are either asymptomatic or exhibit mild-to-modest symptomatology. However, the subpopulations predisposed to autoimmunity, or those with pre-existing autoimmune conditions, may experience detrimental effects; either in an acute clinical context of COVID-19, or through a potential triggering of novel autoimmune conditions via a number of virus-mediated mechanisms $[4,20,21]$.

Research concerning the underlying mechanisms is currently developed, although clinical reports suggest a link between SARS-CoV-2 and autoimmunity, both as a potential causative factor and an exacerbator. For instance, a recent study reported the presence of antiphospholipid antibodies (aPLs) in 47\% (31/66) of critically ill COVID-19 patients, as compared to the non-critically ill ones [22]. Moreover, SARS-CoV-2-induced autoimmunity is also indicated by reports of anti-nuclear antibodies (ANAs), lupus anticoagulant, anti-interferon (IFN) and anti- melanoma differentiation-associated protein 5 (MDA5) antibodies in severely ill patients. A study conducted by Vojdani et al. 2020 demonstrated a potential cross-reactivity of anti-SARS-CoV-2 spike antibodies and the following human tissue proteins, i.e. transglutaminase 3 , transglutaminase 2 , myelin basic protein, mitochondria, nuclear antigen, a-myosin, thyroid peroxidase, collagen, claudin 5+6, and S100B. This, in turn, further contributes to the hypothesis that SARS-CoV-2 may be an aetiological factor of autoimmunity [23]. Furthermore, it has been estimated that approximately $4 \%$ of uninfected patients over the age of 70 possess anti-IFN autoantibodies which contribute to $\sim 20 \%$ of COVID-19 fatalities. This fact has been attributed to mutations in genes involved in the regulation of type I and type III IFN immunity $[24,25]$. However, whether SARS-CoV-2 is able to elicit the production of de novo anti-IFN autoantibodies, remains to be substantiated. Nevertheless, it would be tempting to suggest that mutations in genes associated with IFN immunity may contribute to the ability of SARS-CoV-2 to trigger the production of autoreactive antibodies which target the IFN pathways and IFN itself.

Autoimmune conditions, such as GuillainBarré syndrome (GBS), Miller Fisher syndrome, paediatric immune thrombocytopenia (ITP), immune thrombocytopenic purpura (ITPP), systemic lupus erythematosus (SLE) and Kawasaki disease (KD), have been reported in COVID-19 patients regardless of the acute phase of infection [26-33]. Additionally, multisystem inflammatory disorders in children, phenotypically consistent with the clinical presentation of the Kawasaki disease, have been substantially correlated with acute COVID-19 in a recent report by Rubens et al. [34].

The possible correlation between ITP and COVID-19 is particularly remarkable. In view of two thirds of children diagnosed with ITP have suffered a viral infection, such as cytomegalovirus, hepatitis $C$, herpes, varicella zoster, rubella, Epstein-Barr virus, approximately one month prior to the diagnosis, it is impossible to exclude that SARS-CoV-2 could potentially be a novel aetiological factor of this autoimmune condition [29, 35-39]. The aforementioned paediatric case report of COVID-19-associated ITP could be indicative of the fact that SARS-CoV-2 may act as a viral trigger for autoimmunity in younger indi- 
viduals, or it may exacerbate the existing ITP. The idea of SARS-CoV-2 which would exacerbate the stable ITP (and possibly other autoimmune conditions) may be supported by the case report of a previously stable ITP with infrequent flare-ups transitioning towards acute ITP after immunization with the Pfizer-BioNTech mRNA COVID-19 vaccine [40].

A possible mechanism by which SARS-CoV- 2 may trigger or exacerbate autoimmunity is the phenomenon of molecular mimicry, which presumably occurs when $\mathrm{T}$ or $\mathrm{B}$ cells, induced by pathogen-derived peptides become cross-activated by self-peptides (of the host). In theory, therefore, it is possible that sequence similarities between foreign and self-peptides are sufficient to result in the aforementioned cross-activation $[41,42]$. Structural homology is very important in the theory of molecular mimicry as confirmed by findings of single antibodies or TCR ( $T$ cell receptor) being activated by merely a few crucial residues $[42,43]$. In fact, molecular mimicry may occur at the following levels:

1) complete identification of the viral and host protein,

2) homology between the host and viral protein/s,

3) common or sufficiently similar native or modified (glycosylated) amino acid sequences/epitopes between the virus and the host,

4) structural similarities between viral or environmental agents. Furthermore, viral infections may be followed by epitope spreading, which is a process of an immune response being elicited against viral epitopes which are not pathogenicity factors and display no cross-reactivity with such epitopes [44-47]. Nevertheless, although molecular mimicry has been postulated as a potential causative factor in post-COVID-19 autoimmunity and multi-organ damage, more research is necessary with regard to this hypothesis. By means of in sillico analysis, we investigated whether SARS-CoV-2 peptide sequences could behave similarly to molecular mimics, with a potential to trigger an autoimmune response. The immunogenic potential of the retrieved homologous sequences was validated in terms of their potential to elicit $T$ and $B$ cell responses in terms of their sequential and structural information. In particular, the study comprised the analysis of binding affinity between human leukocyte antigen (HLA)-encoded proteins and the molecular mimics, along with the immunogenicity of continuous and discontinuous predicted $B$ cell epitopes which share $\geq 3$ amino acid sequences (viral proteins).

\section{Methods}

\section{Protein sequences}

SARS-CoV-2 reference protein sequences were retrieved from the National Center for Biotechnology Information (NCBI) database. All of the 28 SARS-CoV-2 proteins were queried when running the BLASTp tool (Table 1).

Table 1. List of NCBI database protein accession numbers used in the BLASTp query. Accession numbers presented in bold are SARS-CoV-2 proteins for which the BLASTp program returned significant $E$ values.

\begin{tabular}{ll}
\multicolumn{1}{c}{$\begin{array}{c}\text { Protein Accession } \\
\text { Number }\end{array}$} & \multicolumn{1}{c}{ Protein name } \\
\hline YP_009724389.1 & ORF1ab polyprotein \\
\hline YP_009725295.1 & ORF1a polyprotein \\
\hline YP_009724390.1 & surface glycoprotein \\
\hline YP_009724391.1 & ORF3a protein \\
\hline YP_009724392.1 & envelope protein \\
\hline YP_009724393.1 & membrane glycoprotein \\
\hline YP_009724394.1 & ORF6 protein \\
\hline YP_009724395.1 & ORF7a protein \\
\hline YP_009725318.1 & ORF7b \\
\hline YP_009724396.1 & ORF8 protein \\
\hline YP_009724397.2 & nucleocapsid phosphoprotein \\
\hline YP_009725255.1 & ORF10 protein \\
\hline YP_009742617.1 & nsp10 \\
\hline YP_009742616.1 & nsp9 \\
\hline YP_009742615.1 & nsp8 \\
\hline YP_009742614.1 & nsp7 \\
\hline YP_009742613.1 & nsp6 \\
\hline YP_009742612.1 & 3C-like proteinase \\
\hline YP_009742611.1 & nsp4 \\
\hline YP_009742610.1 & NSP3 \\
\hline YP_009742609.1 & nsp2 \\
\hline YP_009742608.1 & leader protein \\
\hline YP_009725312.1 & nsp11 \\
\hline YP_009725311.1 & 2'-0-ribose methyltransferase \\
\hline YP_009725310.1 & endoRNAse \\
\hline YP_009725309.1 & 3'-to-5' exonuclease \\
\hline YP_009725308.1 & helicase \\
\hline YP_009725307.1 & RNA-dependent RNA polymerase \\
\hline &
\end{tabular}


Homology search

The BLASTp online tool was utilized to compare SARS-CoV-2 protein accessions (Table 1) to the human proteome, and the query was limited to Homo sapiens (taxid: 9606) in the UniProtKB/ Swiss-Prot database. Both default and modified parameters (expected threshold modified to 1) were used in the analysis. BLASTp results were visualized using Kablamm. The retrieved human proteins with homologous sequences were queried using the Open Targets online repository for human proteins implicated in the disease in order to establish whether any of the retrieved human proteins have been correlated with either autoimmunity, or general inflammatory phenotypes.

\section{Prediction of B cell epitopes}

In order to explore the possibility whether the conserved regions may act as B cell epitopes, the prediction was conducted on the basis of the Immune epitope database (IEDB). From a variety of algorithms available on IEDB, Emini surface accessibility, Kolaskar and Tongaonkar and Bepipred were used. Homologous SARS-CoV-2 amino acid sequences retrieved from the BLASTp results were queried in their full length. Validation of whether the retrieved sequences could act as $B$ cell epitopes on a structural level, was performed using the ElliPro server, which uses a protein data bank (PDB) format as input. PDB crystal structures for each of the 28 SARS-CoV-2 proteins were retrieved from PDB and prepared for docking using PyMOL [48]. ElliPro retrieves both linear and discontinuous antibody epitopes based on the provided crystal structure, using algorithms rooted in the protein shape approximation along with the clustering of neighbouring residues, and the residue protrusion index. Default search parameters were maintained during the utilization of each of the aforementioned tools.

\section{Prediction of T cell epitopes}

The selected viral protein sequences were subjected to HLA-II binding analysis on 3/16/2021 using the IEDB analysis resource SMM-Align (ver. 1.1) tool [49]. Outputs generated by the SMM-Align method are given in units of inhibitory concentration $50 \mathrm{nM}$, therefore, lower IC50nm values indicated high binding affinity. According to the guidelines provided on IEDB, inhibitory concen- tration (IC) 50 values $<50 \mathrm{nM}$ are considered to be binders of high affinity, $<500 \mathrm{nM}$ of intermediate affinity, whereas $<5000$ nM of low affinity.

Potential binders (IC50 < 100) generated by the MHC-II binding prediction tool were further analysed and visualized using LigPlot $^{+}$, a tool which generates 2D ligand-protein interaction diagrams (50). Docking simulations between the potential binders and MHC-II alleles were conducted through the GalaxyPepDock online docking server, using crystal structures of HLA-DRB1 (PDB ID: 6BIN), HLA-DQ2.3 (PDB ID: 4D8P) and HLA-DR (PDB ID: 4H26) (51). Prior to docking simulations, the resident peptide, the accompanying solvent (water), and any other ligands provided within the PDB files, were removed.

\section{Results}

Homology between SARS-CoV-2 proteins and human proteins implicated in autoimmune and non-autoimmune conditions Interestingly, out of the 28 SARS-CoV-2 proteins which were queried against the human proteome, homology was found between the viral open reading frame (ORF) 1a, ORF1ab, ORF7b and the multi-domain non-structural protein 3 (NSP3), as well as the human proteins mono-ADP-ribosyltransferase (PARP14), mono-ADP-ribosyltransferase (PARP9), ADP-ribose glycohydrolase (MACROD1) and the low-density lipoprotein receptor-related protein 2 (LRP2) (refer to Table 1).

In terms of the default BLASTp search parameters, ORF1a and ORF1ab and NSP3 were found to have sequences homologous with PARP14, PARP9 and MACROD1 (Figures 1-9), whereas homology between ORF7b and LRP2 was obseved only after running a second query where the expected threshold was modified to 1 (Figure 10). The homologous regions between ORF7b and LRP2 returned no significant results once analysed for their ability to act as $T$ and $B$ cell epitopes.

PARP9 and PARP14 play pivotal roles in the eukaryotic physiology, and have been strongly implicated in COVID-19. In spite of the fact that PARP protein family is generally relatively obscure with regard to their functionality under normal physiological conditions, both 
Table 2. BLASTp results obtained following the query of 38 SARS-CoV-2 proteins against the human proteome

\begin{tabular}{|c|c|c|c|c|c|c|c|c|}
\hline $\begin{array}{c}\text { Viral } \\
\text { protein }\end{array}$ & Human protein & $\begin{array}{l}\text { Max } \\
\text { Score }\end{array}$ & $\begin{array}{l}\text { Total } \\
\text { Score }\end{array}$ & $\begin{array}{l}\text { Query } \\
\text { Cover }\end{array}$ & E value & Per. ident & Acc. Len & Accession \\
\hline \multirow[t]{3}{*}{ ORFla } & PARP14 & 56.2 & 56.2 & $2 \%$ & $5.00 \mathrm{E}-07$ & 32.26 & 1801 & Q460N5.3 \\
\hline & PARP9 & 50.1 & 50.1 & $2 \%$ & $3.00 \mathrm{E}-05$ & 30.99 & 854 & Q8IX06.2 \\
\hline & MACROD1 & 42.7 & 42.7 & $3 \%$ & 0.003 & 28 & 325 & Q9B069.2 \\
\hline \multirow[t]{3}{*}{ ORF1ab } & PARP14 & 56.2 & 56.2 & $1 \%$ & $8.00 \mathrm{E}-07$ & 32.26 & 1801 & Q460N5.3 \\
\hline & PARP9 & 50.4 & 50.4 & $1 \%$ & $4.00 \mathrm{E}-05$ & 30.99 & 854 & Q8IX06.2 \\
\hline & MACROD1 & 42.7 & 42.7 & $1 \%$ & 0.005 & 28 & 325 & Q9BQ69.2 \\
\hline ORF7b & LRP2 & 26.2 & 26.2 & $51 \%$ & 0.55 & 60.87 & 4655 & P98164.3 \\
\hline \multirow[t]{3}{*}{ NSP3 } & \begin{tabular}{|l|} 
PARP14 \\
\end{tabular} & 57.4 & 57.4 & $5 \%$ & $9.00 \mathrm{E}-08$ & 32.26 & 1801 & Q460N5.3 \\
\hline & PARP9 & 51.2 & 51.2 & $6 \%$ & $7.00 \mathrm{E}-06$ & 30.99 & 854 & Q8IX06.2 \\
\hline & MACROD1 & 41.6 & 41.6 & $7 \%$ & 0.003 & 27.81 & 325 & Q9BQ69.2 \\
\hline
\end{tabular}

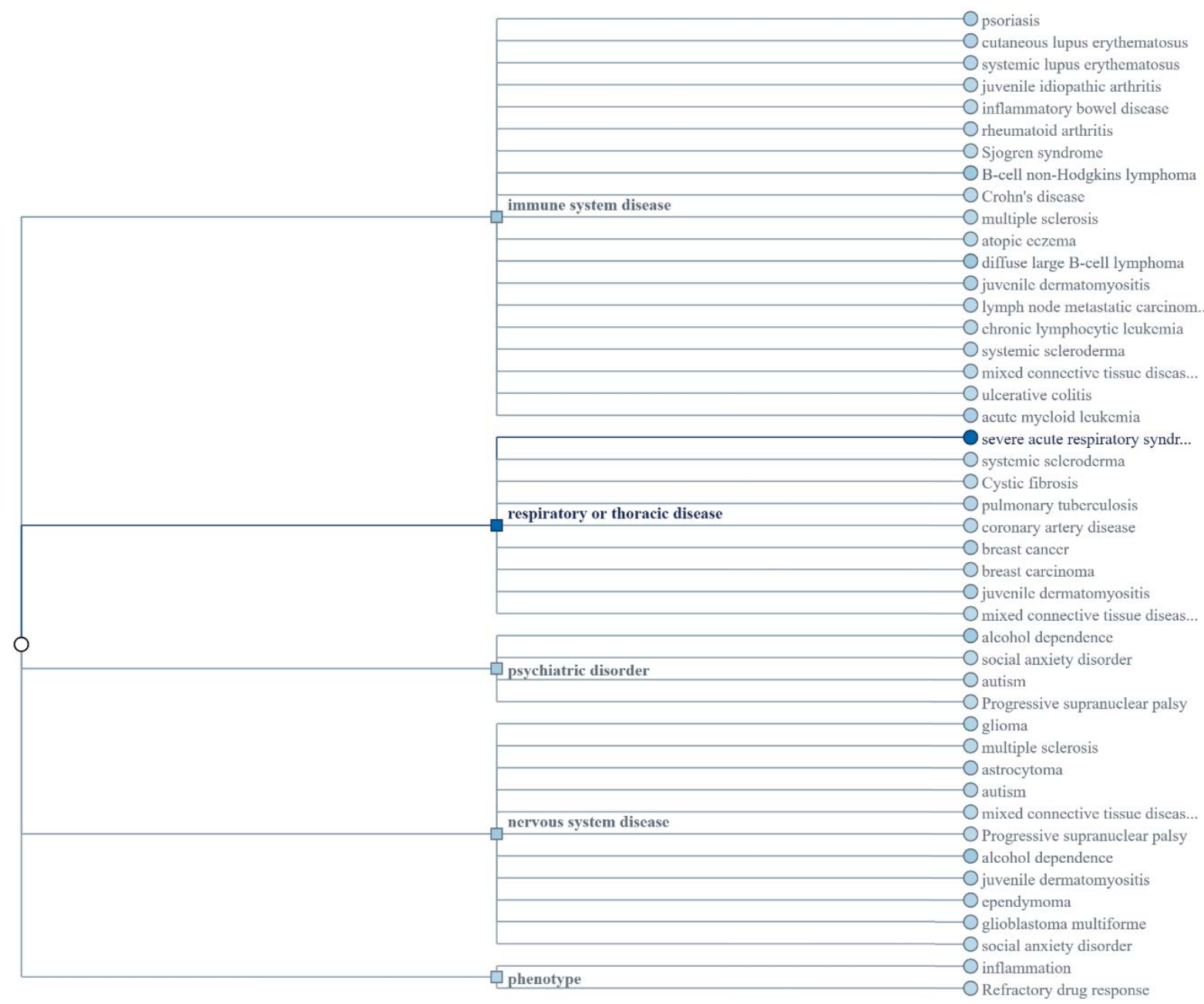

Figure 1. Diseases and phenotypes associated with PARP9 


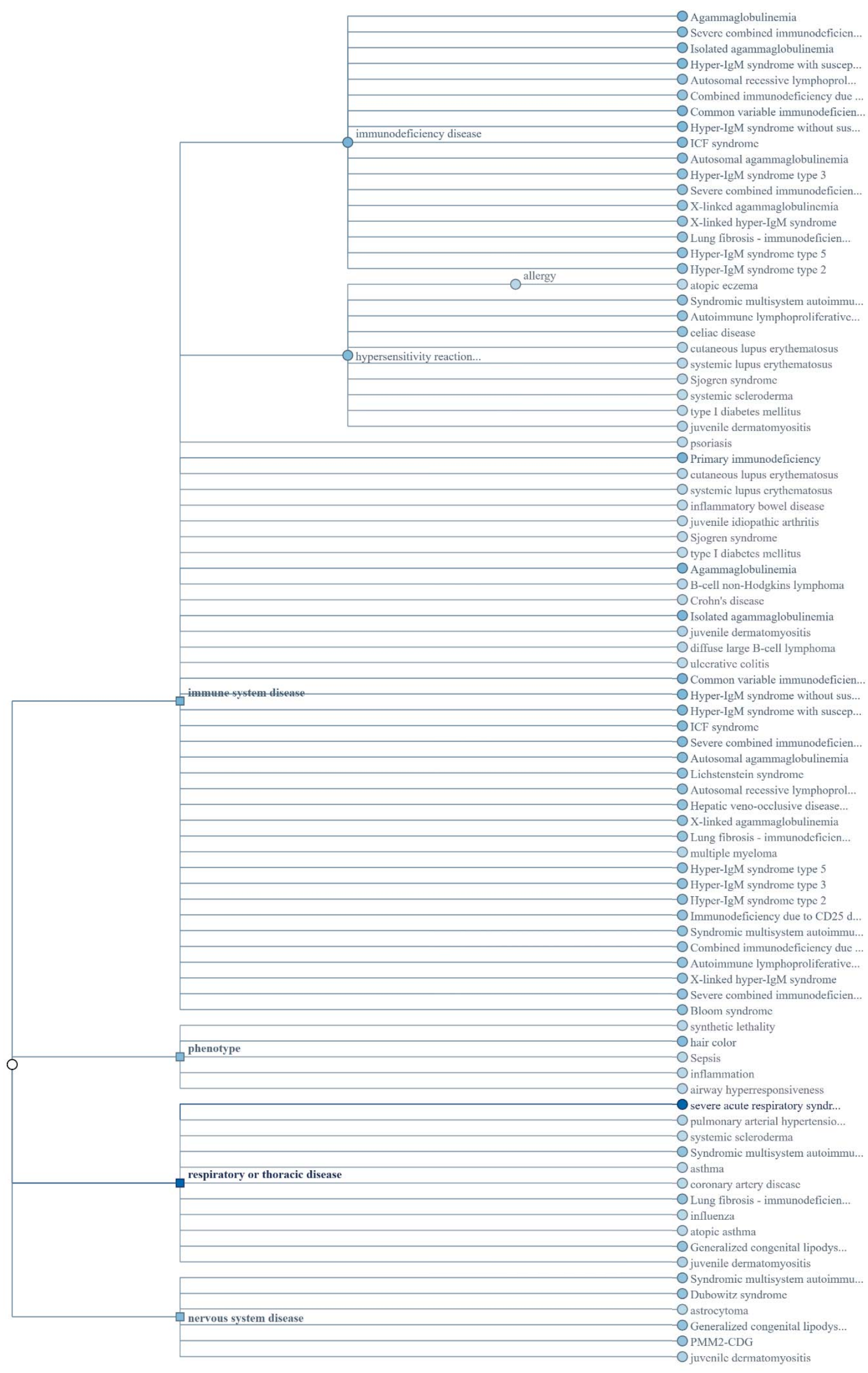

Figure 2. Diseases and phenotypes associated with PARP14 


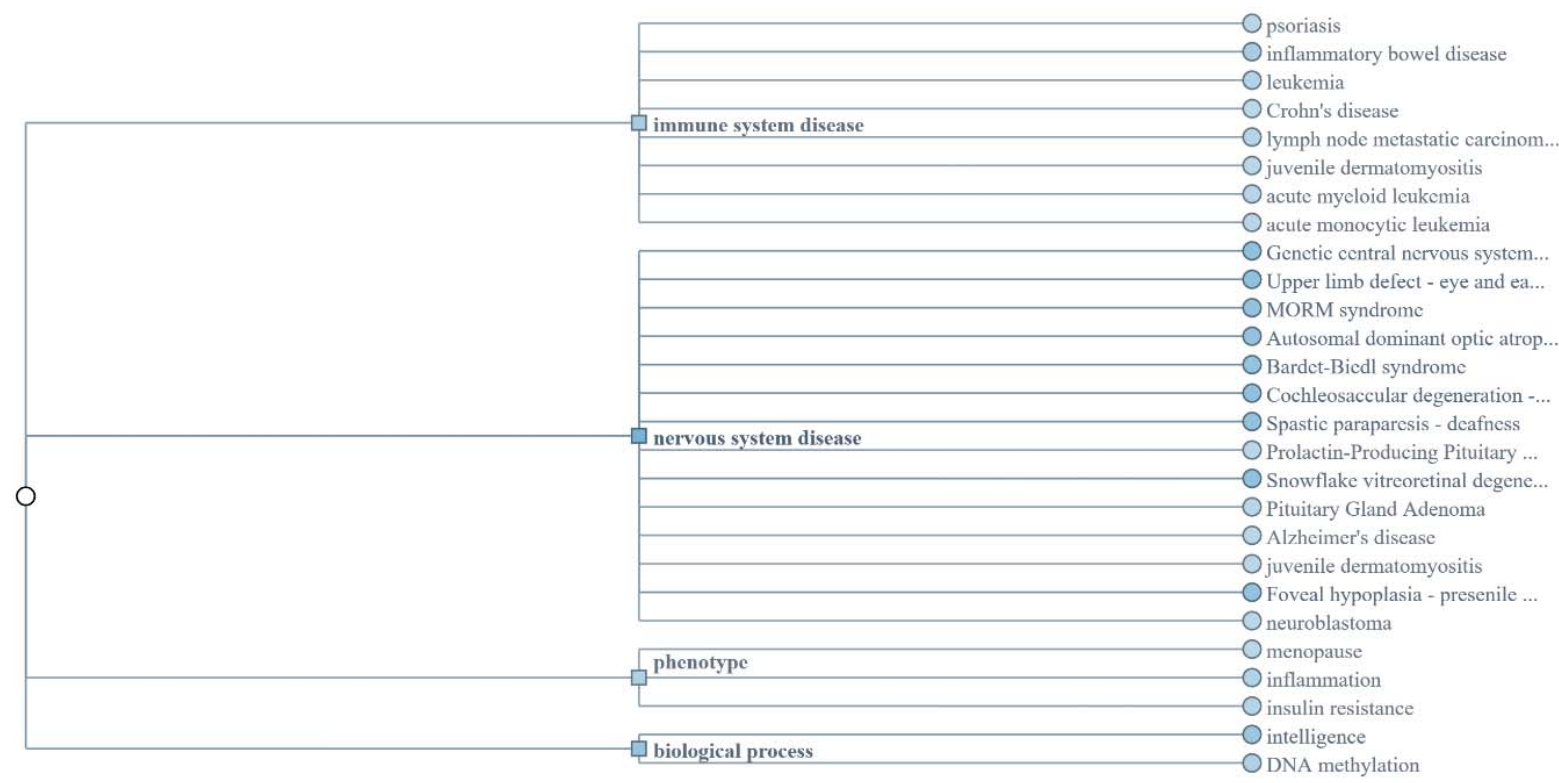

Figure 3. Diseases, phenotypes and biological processes associated with MACROD1

of these proteins hold significant roles in host interferon (IFN)-mediated antiviral defence and DNA repair. Specifically, PARP9 and PARP14 play two opposing roles in IFNy-induced macrophage activation, where PARP9 promotes IFNY responses, whereas PARP14 suppresses them by preventing the phosphorylation of STAT1. Additionally, MACROD1 is notably a promiscuous mitochondrial protein that regulates mitochondrial function and plays a role in DNA repair. Although knowledge on the function of MACROD1 remains incomplete, it is highly enriched in tissues which are energetically demanding, such as the heart or the musculoskeletal system. Furthermore, recent studies have correlated MACROD1 and MACROD2 knockouts with neurological dysfunction and cancer. Querying PARP14, PARP9 and MACROD1 in the OpenTargets platform revealed a strong association with a wide spectrum of human diseases spanning across multiple organ systems, a great number of which possess an autoimmune component in their aetiology (Figures 1-3).

\section{Potential B cell epitopes}

In order to further verify the hypothesis that molecular mimics play a role in COVID-19 associated autoimmunity, we analysed identified homologous sequences for the presence of structural and linear B cell epitopes, which, in turn, measure their ability to stimulate the auto-reactive antibodies production. Interestingly, out of all the proteins containing homologous regions, only NSP3 - a replication/transcription SARS-Cov-2 protein - contained a tripeptide ( $L K H)$ homologous with the human proteome on a conformational level, at two different regions. Moreover, a search for linear epitopes using the aforementioned three algorithms, did not provide significant results in terms of antibody production potential for the specific conserved sequences (data not shown) (Figures 4-5). 


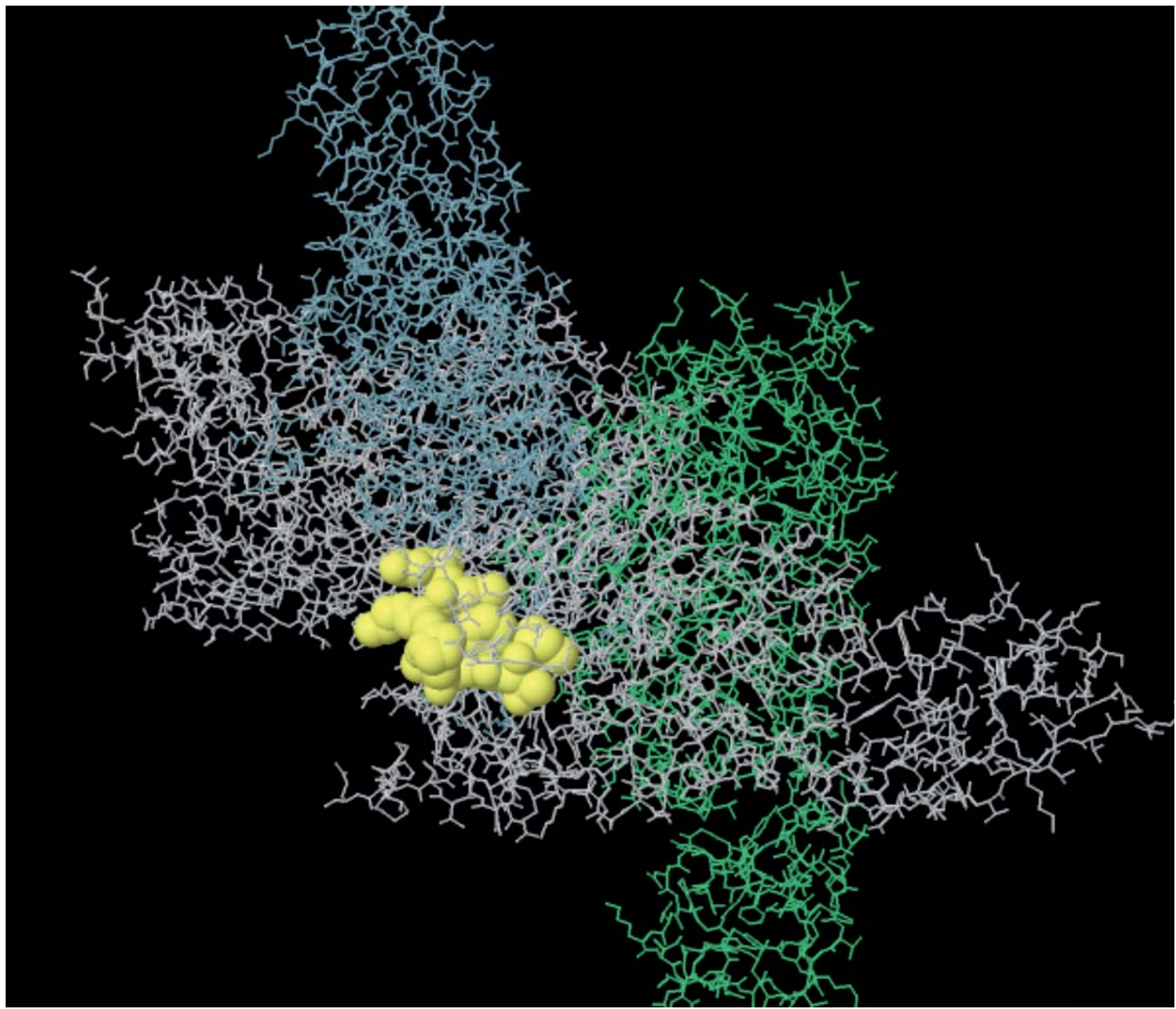

Figure 4. Three-dimensional render of the region within the NSP3 SARS-CoV-2 protein which contains the conformational LKH epitope (highlighted in yellow). The image was rendered using the ElliPro online server

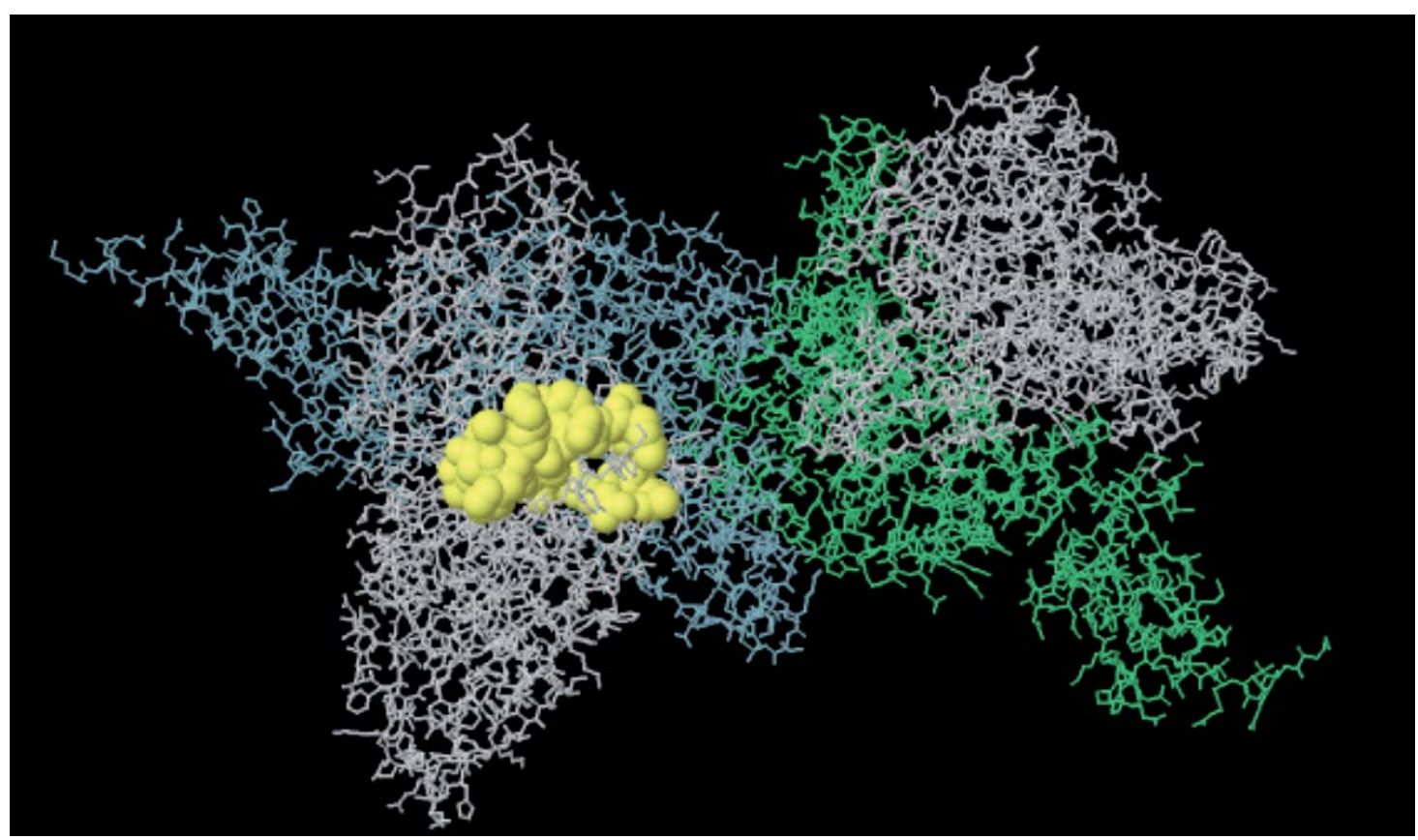

Figure 5. Three-dimensional render of the region within the NSP3 SARS-CoV-2 protein which contains the conformational LKH epitope (highlighted in yellow). The image was rendered using the ElliPro online server 
Homologous peptides may act as HLA-II binding motifs

In terms of molecular mimicry, in order for breakdown of immunological tolerance towards self-peptides to occur, the intensity of the immune response elicited by human mimic peptides should presumably be sufficiently similar to that of viral peptides. Therefore, the HLA class II encoded HLA-DR-peptide and HLA-DQ-peptide complex structures were evaluated for their ability to bind both viral-derived and human-derived peptides within the binding groove of HLA. The HLA molecules selected in this study predominantly present exogenous antigens to CD4+ T helper cells $\left(T_{h}\right)$, and their correlation with a broad spectrum of autoimmune disease has been well established [52-58]. In order to determine whether any of the homologous sequences retrieved by

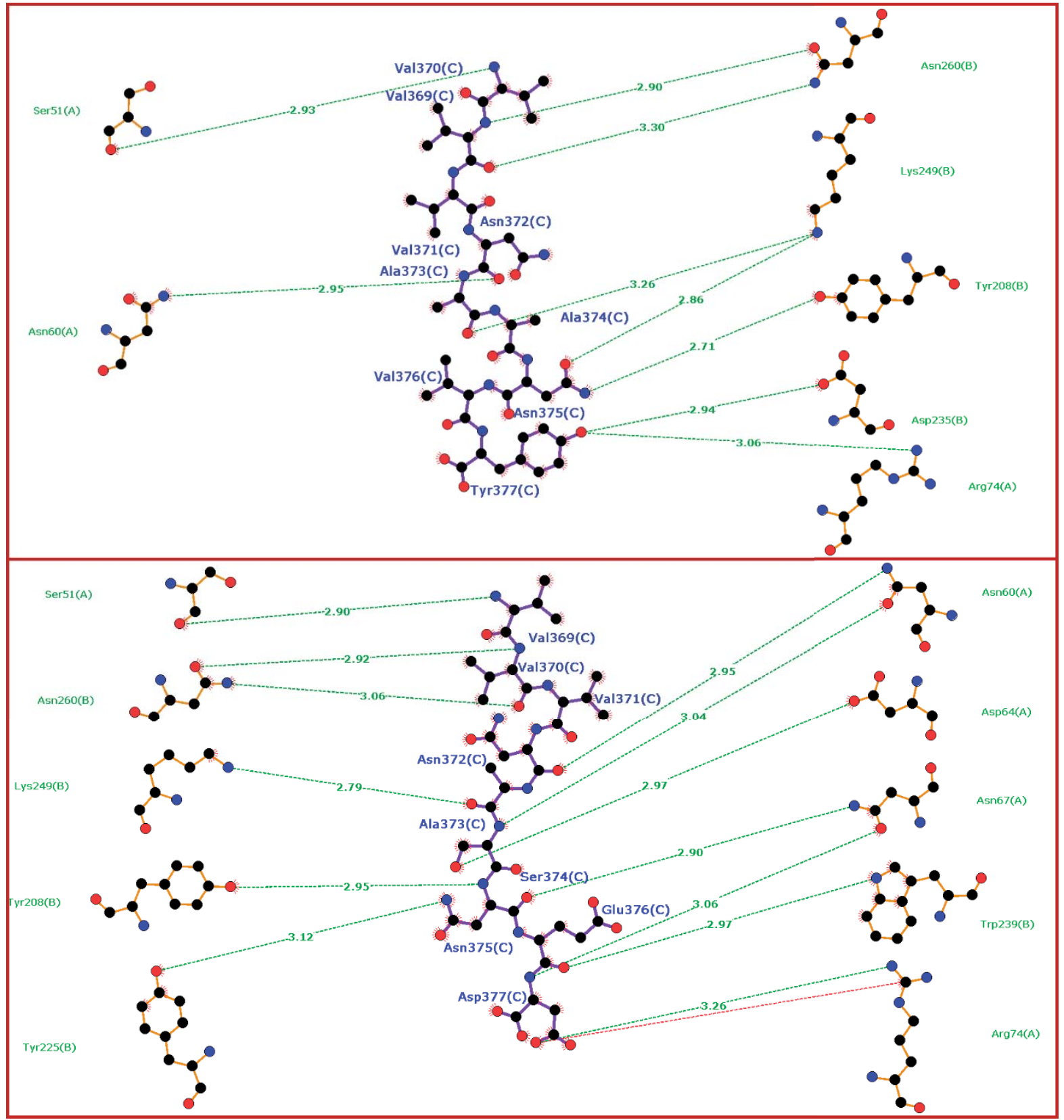

Figure 6. LigPlot-generated diagram of homologous viral (top) and human (bottom) peptides docked with the HLA-DRB1 binding groove. The viral peptide (VVVNAANVY) stems from ORFla, while the human homologue (VVVNASNED) stems from MACROD1. Carbon atoms are coloured black, oxygen atoms are coloured red, nitrogen atoms are coloured blue. The bonds between $\mathrm{C}$ atoms coloured orange belong to HLA-DRB1 residues, whereas the bonds between $\mathrm{C}$ atoms belonging to the ligand peptide are coloured blue. Hydrogen bonds are represented with green lines. The red lines represent salt bridges 
the BLASTp query could act as T cell epitopes, potential binders were generated after analysing the sequences using the IEDB analysis resource SMM-Align tool. The SMM-Align tool analysed the sequences for their ability to bind to 12 HLA-DR and 12 HLA-DQ alleles, the results of which are summarized in Table 2. Although the SMM-Align method automatically calculates binding ener- gy and thus offers considerable insight into the immunogenicity of the peptide in the context of MHC-II, LigPlot diagrams were generated as to to visualize the key residues which would play a part in these MHC-II-peptide dockings. SMM-Align generates both lone core sequences and core sequences with flanking residues; however, the binding affinity of flanked core sequences is sig-

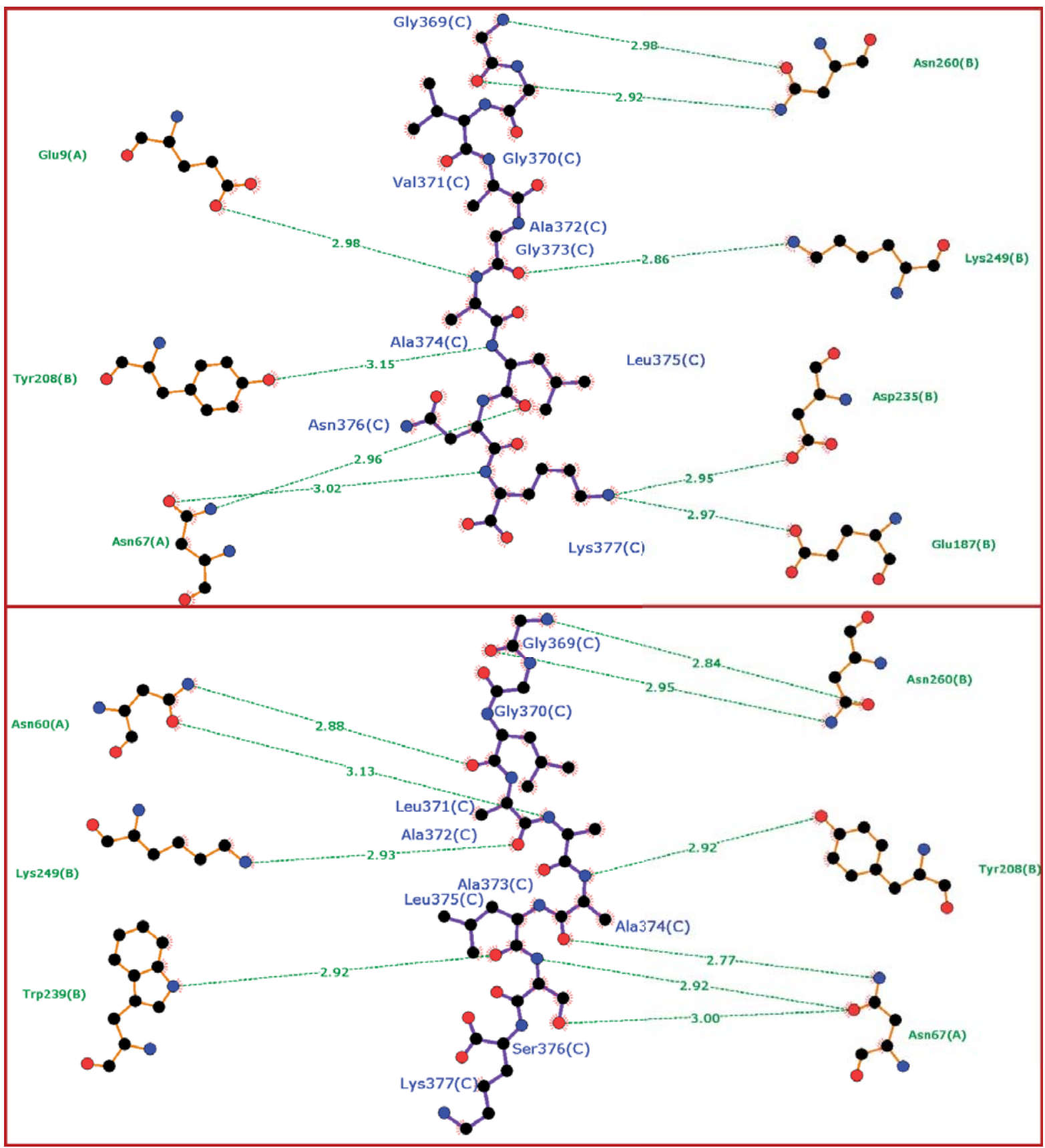

Figure 7. LigPlot-generated diagram of homologous viral (top) and human (bottom) peptides docked with the HLA-DRB1 binding groove. The viral peptide (GGVAGALNK) stems from ORFla, while the human homologue (GGLAAALSK) stems from PARP9. Carbon atoms are coloured black, oxygen atoms are coloured red, nitrogen atoms are coloured blue. The bonds between $C$ atoms coloured orange belong to HLA-DRB1 residues, whereas the bonds between $C$ atoms belonging to the ligand peptide are coloured blue. Hydrogen bonds are represented with green lines 
nificantly influenced by the core itself $(59,60)$. Hence, both core and flanked core sequences with low IC50 values were docked with the HLA binding groove. Docking simulations with flanked cores can be found as PDB files in Supplementary File 1, with the SMM-Align results being available in Supplementary File 2. The length of hydrogen bonds between residues in the HLA binding pockets, as well as the peptides themselves were taken as indicators of peptide stability within the pocket binding groove. A distance of $\leq 3.5 \mathrm{Ang}$ stroms $(\AA)$ was considered indicative of good peptide stability.

The viral peptide VVVNAANVY and its human counterpart VVVNASNED, docked with HLA-DRB1, display high stability within the binding groove,

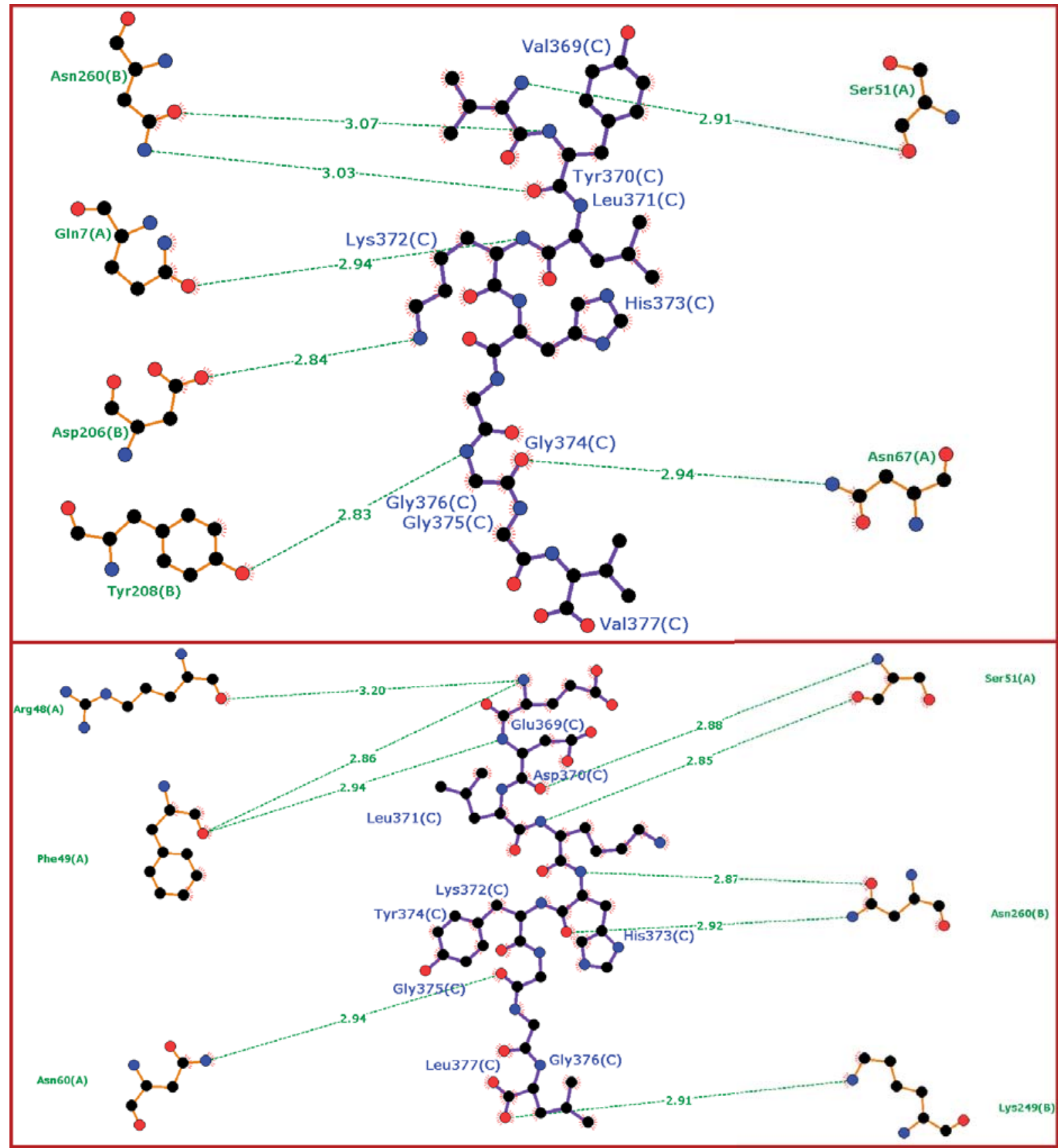

Figure 8. LigPlot-generated diagram of homologous viral (top) and human (bottom) peptides docked with the HLA-DRB1 binding groove. The viral peptide (VYLKHGGGV) stems from ORF1a, while the human homologue (EDLKHYGGL) stems from PARP14. Carbon atoms are coloured black, oxygen atoms are coloured red, nitrogen atoms are coloured blue. The bonds between $\mathrm{C}$ atoms coloured orange belong to HLA-DRB1 residues, whereas the bonds between $\mathrm{C}$ atoms belonging to the ligand peptide are coloured blue. Hydrogen bonds are represented with green lines 
with a notable number of identical HLA residues (Ser51, Asn60, Asn260, Lys249, Tyr208, Arg74) interacting with both peptides at similar hydrogen bond lengths, within the $3.5 \AA$ threshold (Figure 6). Furthermore, the peptides GGVAGALNK (viral derived) and GGLAAALSK (human derived) demonstrate high stability within the HLA-DRB1 binding groove, similarly interacting with several identical binding groove residues (Asn260, Asn67, Lys249, Tyr208) (Figure 7). Figure 8 presents the docked viral (VYLKHGGGV) and human (EDLKHYGGL) peptides interact with fewer identi-

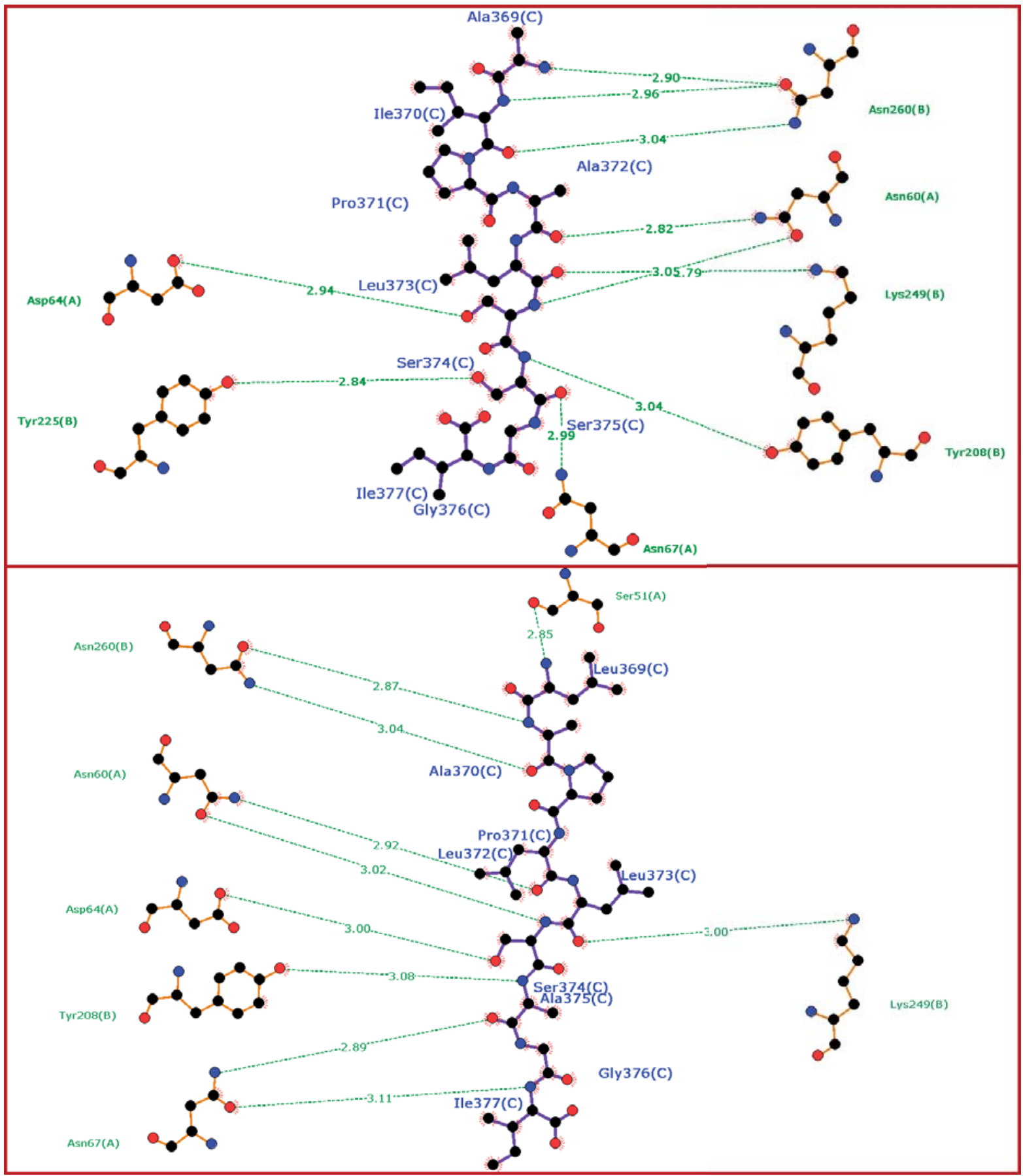

Figure 9. LigPlot-generated diagram of homologous viral (top) and human (bottom) peptides docked with the HLA-DRB1 binding groove. The viral peptide (LAPLLSAGI) stems from ORF1a, while the human homologue (AIPALSSGI) stems from PARP14. Carbon atoms are coloured black, oxygen atoms are coloured red, nitrogen atoms are coloured blue. The bonds between $C$ atoms coloured orange belong to HLA-DRB1 residues, whereas the bonds between $\mathrm{C}$ atoms belonging to the ligand peptide are coloured blue. Hydrogen bonds are represented with green lines 
cal residues, namely Asn260 and Ser51; however, the valine present in the viral-derived sequence and the leucine present in the human-derived sequence are functionally equivalent. In contrast, the viral peptide LAPLLSAGI and its human homologue AIPALSSGI demonstrate much higher binding homogeneity, with both peptides similarly interacting between identical residues (Asp64, Asn260, Asn60, Lys249, Tyr208, Asn67) at acceptable hydrogen bond lengths. In spite of the evident differences in amino acids which constitute these peptides, they share a high percentage of functionally equivalent amino acids (Figure 9).

\section{Discussion}

Viral infections have been intensely investigated for their potential to trigger a breakdown of immunological tolerance through the phenomenon of molecular mimicry, where viral protein sequences homologous with sequences of the human proteome may elicit $\mathrm{T}$ cell or B cell responses through cross-reactivity. Prior to correlating this process with SARS-CoV-2-mediated autoimmunity, several crucial factors of autoreactivity must be considered. Firstly, autoreactive antibodies are a natural part of the human immunoglobulin repertoire, although their binding affinity towards self-antigens is relatively weak, thus failing to contribute to phenotypes characteristic of autoimmunity. In fact, autoreactive antibodies appear to contribute to numerous homeostatic repair mechanisms, which is probably possible due to their weak binding affinity towards self-antigens. Moreover, autoreactive $T$ cells are equally prominent in healthy individuals and their homeostatic maintenance is conferred through various tolerogenic mechanisms [61, 62]. In spite of the fact that majority of these mechanisms are not completely understood, the correlation between pathogen-induced inflammatory responses and the breakdown of immunological tolerance has been well documented for a number of virological agents. Nevertheless, the breakdown of immunological tolerance implies the dysregulation of the existing auto-reactive T cells (and B cells for that matter), stimulating the production and subsequent inclusion of the novel auto-reactive $T$ cells into the $T$ cell repertoire. This process may be triggered during viral infections through inter- molecular and intramolecular epitope spreading; with molecular mimicry as a prelude to this process. It is vital to note that the same mechanism may apply for B cells that produce autoantibodies, particularly when discussing the role of autoreactive $\mathrm{CD} 4^{+}$cells and their role in autoimmunity overall. However, in either case, arguably the most elegant and definitive examples of epitope spreading stem from research on demyelinating autoimmune conditions, such as multiple sclerosis, and revolve around interactions between professional antigen-presenting cells (APCs), autoreactive $\mathrm{CD} 4^{+}, \mathrm{CD}^{+} \mathrm{T}$ cells and autoreactive $B$ cells, as key mediators of sustained demyelination [63]. In fact, these key mechanisms appear to be similar in other autoimmune conditions.

The mechanisms by which SARS-CoV-2 molecular mimics may initiate post-infection autoimmunity are multiple, and primarily rooted in the concept of epitope spreading. Based on findings from the previous research on this phenomenon, it may be suggested that local antigen APCs initiate this process when they come to contact with autoreactive $T$ and $B$ cells which had migrated to the inflammation site [63, 64]. This, however, does not exclude dendritic cell (DC)mediated priming of autoreactive lymphocytes within lymphoid organs. Thus, we suggest that, upon coming to contact with professional APCs presenting SARS-CoV-2 molecular mimics, autoreactive $T$ and $B$ cell subpopulations may promote three distinct and non-mutually exclusive immunopathologic continua, i.e.:

1) the lymphocytes may promote extensive organ damage at the site of infection and immune dysregulation (Figure 10) [65];

2) creation of a "fertile field" as a prelude to post-COVID-19 autoimmunity [42, 66-68];

3) initiation of intermolecular and intramolecular epitope spreading (Figure 11) [43-45, 64, 69, 70].

The first scenario implies the absorption of SARS-CoV-2, or its fragments, particularly these belonging to the ORFla polyprotein, from the apoptotic infected cells by resident APCs, such as macrophages and DCs, which possibly depends on TCR specificity $[71,72]$. CD $4^{+}$cells expressing TCRs which promiscuously interact with self-peptides and their presumed molecular mimics, may immunomodulate macrophages and natural killer (NK) cells to destroy tissues expressing self-pro- 


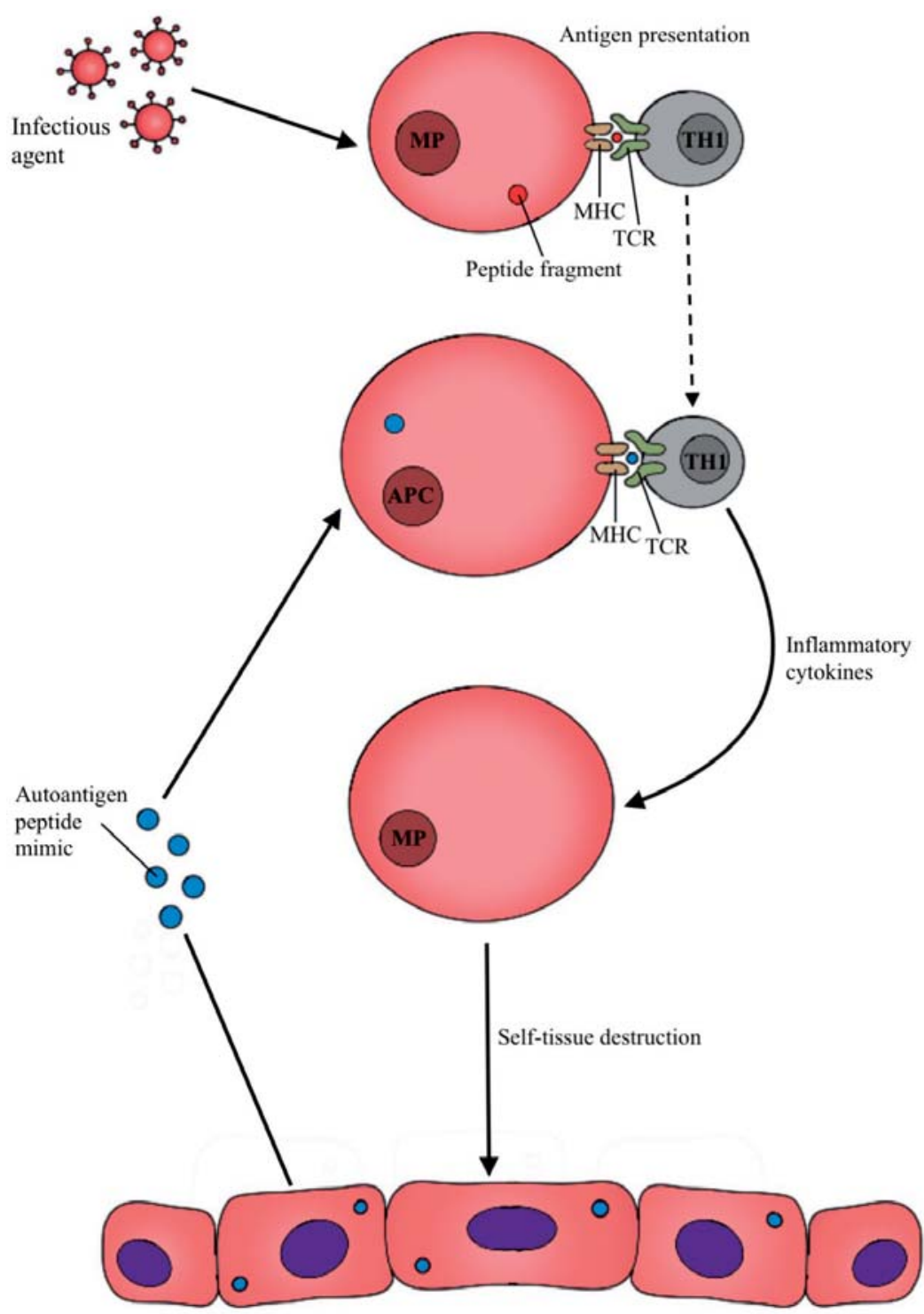

Figure 10. This illustration shows the case of acute self-tissue destruction mediated by the phenomenon of molecular mimicry, during the viral stage of COVID-19. Once a macrophage (MP) has processed the infectious agent, it presents the pathogen peptides containing the molecular mimic, to autoreactive $\mathrm{CD}^{+}{ }^{+} \mathrm{T}$ helper cells (TH1) via the major histocompatibility complex (MHC) II. This may be followed by a subsequent interaction between the same $\mathrm{CD} 4^{+} \mathrm{T}$ helper cell and another antigen-presenting cell (APC) presenting the human-derived peptide mimic. Consequently, this cross-reactivity may prime the autoreactive lymphocyte to modulate self-destructive activities of macrophages via cytokine secretion

teins containing mimic regions; in this case MACROD1, PARP14 and PARP9 [73-75]. Alternatively, one lymphocyte may express two TCRs which promiscuously interact with two or more molecular mimics, thus, increasing the chance of self-oriented immunopathology and further epitope spreading $[61,76,77]$. Alternatively, a single $T$ cell may interact with a macrophage which presents a human peptide fragment containing the mimic, followed by a subsequent interaction with an APC which presents the viral-derived mimic peptide [78]. Haematological findings from COVID-19 patients support the first scenario, as macrophages and NK cells have been substantially correlated with the extensive immunopathology documented in severe cases, where macrophages comprise for the key mediators of severe cytokine storm and overall pathogenesis 
enhancement $[79,80]$. Although this process is well within the viral phase of infection rather than within the scope of the post-infection autoimmunity, it adequately complements the current clinical data regarding organ damage associated with COVID-19 patients, and maintains the mimicry hypothesis.

Secondly, cross-reactivity with molecular mimics does not necessarily have to induce an immediate autoimmune response directed towards the tissues which abundantly express MACROD1, PARP14 and PARP9. Alternatively, much as other autoimmunity-associated viruses, SARS-CoV-2 could create a "fertile field" - a term which encompasses molecular mimicry, epitope spreading and viral persistence [81]. This would be induced by the substantial immune dysregulation caused by SARS-CoV-2, where the optimal conditions for autoreactive $\mathrm{CD} 4^{+}$and $\mathrm{CD} 8^{+} \mathrm{T}$ cells and $B$ cells to become primed against regions within PARP14, MACROD1, PARP9, and potentially other self-proteins, would be created. Nonetheless, whether these primed cells initiate an immune response during the viral stage of COVID-19, likely depends on the level of immunopathology in the course of infection. For instance, an increased pro-inflammatory cytokine expression has been reported as a prerequisite for the creation of the "fertile field" in certain virus-mediated autoimmunity models, and cytokine dysregulation is certainly considered a hallmark of COVID-19 [9, $67,82,83]$. Once the "fertile field" has been established, subsequent infections with the unrelated pathogens - viral or bacterial - may trigger a profound autoimmune response mediated by the primed autoreactive lymphocytes.

The third scenario, which represents an integrative component of the aforementioned two, entails not only cross-reactivity with PARP9, MACROD1 and PARP14, but also the potential to extend the epitopes containing molecular mimics beyond the ones we have identified for these proteins (intermolecular spreading). In addition, a formation of an immune response against PARP14, MACROD1 and PARP9, may trigger epitope spreading directed towards other proteins, including those belonging to the PARP protein family, or MACROD2 (intramolecular spreading). Consequently, this results in $T$ and $B$ cell epitope diversification, which may account for the fact that a variety of autoimmune diseases have been reported in patients who have recovered from COVID-19 [2, 4, 21, 26, 27, 29, 30, 32, 33, 84].

Concluding, we have identified several homologous regions between the SARS-CoV-2 proteome and the human proteins PARP14, PARP9 and MACROD1, which may potentially behave as molecular mimics. The results obtained from molecular docking simulations between MHC-II and the identified regions, both viral and their

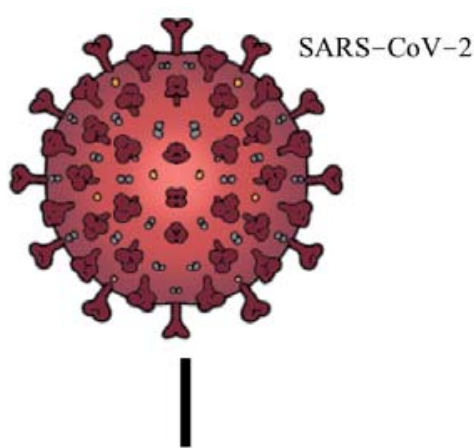

Cross reactivity with self-peptides

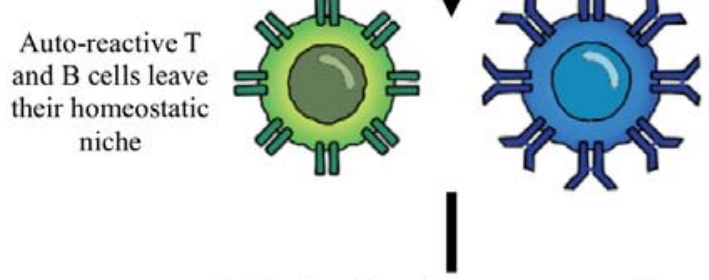

Production of pro-inflammatory cytokines and autoantibodies

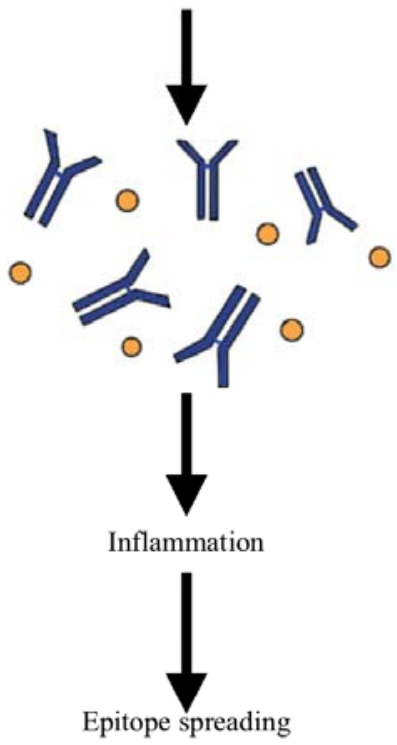

Figure 11. A schematic representation of the process of molecular mimicry-initiated process of epitope spreading, without an immediate initiation of self-tissue destruction 
counterparts, prompted the conclusion that these potential mimics may be presented to autoreactive $\mathrm{CD}^{+}$and $\mathrm{CD} 4^{+} \mathrm{T}$ cells, in an identical or similar way to their human homologues, thus priming this lymphocyte subset towards an autoimmune response. Moreover, a prerequisite for these naturally-occurring $T$ cells to leave their homeostatic niche, would be the creation of a "fertile field" by SARS-CoV-2-induced immune dysregulation; particularly in the context of cytokine dysregulation. This may result in either immediate and severe tissue destruction of cells containing the mimic peptides by autoreactive $\mathrm{T}$ cell-mediated macrophages, or in priming of the autoreactive repertoire of $T$ cells in the absence of autoimmunity. In this case, these inert, yet primed, lymphocytes, may be prompted to leave their homeostatic niche and direct self-tissue destruction where PARP14, PARP9 and MACROD1 are abundant. In terms of the autoantibodies, although the number of linear and conformational $B$ cell epitopes identified in our research is scarce, the results suggest the possibility that these homologous regions may prompt autoreactive $B$ cells to produce antibodies for these epitopes, particularly the $L K H$ tripeptide. Therefore, we were able to develop a plausible case - based on in sillico analysis - where molecular mimicry potentially constitutes an aetiological mechanism of SARS-CoV-2-mediated autoimmunity, whether in a multi-organ damage context, or outside the viral phase of infection. This and other studies further support the notion that COVID-19 survivors may be prone to the elicitation or exacerbation of autoimmune conditions, due to the extensive immune dysregulation caused by the virus. Epidemiologically, this may be evaluated by means of a broader epidemiological surveillance of COVID19 survivors, supplemented by serological cohort studies aimed at detecting autoantibodies and the presence of potential IFN I and IFN III gene mutations which could contribute to post-COVID19 autoimmunity. The aforementioned findings would be indispensable in understanding the role of SARS-CoV-2 as a potential trigger of autoimmunity. Interestingly, this is the first time that the peptide sequence of MACROD1 has been implicated in COVID-19 autoimmunity. We also confirm that PARP9 and PARP14 may be involved, which is consistent with the previously published findings concerning the effects of these two proteins in COVID-19-related autoimmunity [8]. Moreover, our findings corroborate those of the previous study of homologous sequences between PARP14 and SARS-CoV-2 ADP ribose 1'-phosphate. In fact, our approach focused on structural biology which further enhanced the aforementioned and other bioinformatic studies pertaining to this topic. An encouraging finding of this study is the lack of significant BLASTp results related to the homology between the human proteome and the SARS-CoV-2 S protein, particularly since the $S$ protein sequence forms the antigen employed in the currently-approved COVID-19 vaccines. Furthermore, more extensive in vivo research should be conducted with regard to these peptide sequences, in order to determine their relevance for autoimmunity to address the limitations of in sillico analysis, which been thoroughly discussed in recent years, particularly with regard to the immunoinformatic approaches. Nevertheless, the limitations of this study need to be taken into account, and the study should be regarded as indicative rather than definitive. As more data are collected to complement the existing immunoinformatic algorithms, along with improvements in molecular docking technology, the precision of such studies shall undoubtedly increase. Presently, the tools used to conduct this study, as well as the results obtained by their use, are of sufficiently high quality to supplement and clarify the hypothesis presented in this paper. However, in vivo studies are indispensable to confirm any results obtained within in sillico research.

\section{Acknowledgements}

Special thanks go to prof. Andrej Gajić from National Geographic, for his continuous support and mentoring throughout this and other works of the author related to tuberculosis; prof. Monia Avdić, Ph.D., from International Burch University, for her mentoring in the subject of immunology and microbiology, and to all friends and colleagues who have supported this work with their unbiased critique.

\section{Conflict of interest statement}

The authors declare no conflict of interest.

\section{Funding sources}

There are no sources of funding to declare.

\section{References}

1. Zhu N, Zhang D, Wang W, Li X, Yang B, Song J, et al. A novel coronavirus from patients with pneumonia in 
China, 2019. New England Journal of Medicine [Internet]. 2020 Feb 20 [cited 2020 Apr 5];382(8):727-33. Available from: http://www.nejm.org/doi/10.1056/ NEJMoa2001017.

2. Halpert G, Shoenfeld Y. SARS-CoV-2, the autoimmune virus. Autoimmunity Reviews [Internet]. 2020 Dec 1 [cited 2021 Jan 27];19(12):102695. Available from: https://www.ncbi.nlm.nih.gov/pmc/articles/ PMC7598743/.

3. Kim B, Deshpande Kaistha S, Rouse BT. Viruses and autoimmunity. Autoimmunity [Internet]. 2005 Dec [cited 2021 Jan 27];38(8):559-65. Available from: https://www.tandfonline.com/doi/ abs/10.1080/08916930500356583.

4. Caso F, Costa L, Ruscitti P, Navarini L, del Puente A, Giacomelli R, et al. Could Sars-coronavirus-2 trigger autoimmune and/or autoinflammatory mechanisms in genetically predisposed subjects? Autoimmunity Reviews [Internet]. 2020 May 1 [cited 2021 Jan 27];19(5):102524. Available from: https://www.ncbi. nlm.nih.gov/pmc/articles/PMC7271072/.

5. Du RH, Liang LR, Yang CQ, Wang W, Cao TZ, Li M, et al. Predictors of mortality for patients with COVID19 pneumonia caused by SARSCoV- 2: A prospective cohort study. European Respiratory Journal [Internet]. 2020 May 1 [cited 2020 Oct 27];55(5). Available from: https://doi.org/10.1183/13993003.005242020.

6. Ruan $Q$, Yang $K$, Wang W, Jiang L, Song J. Clinical predictors of mortality due to COVID-19 based on an analysis of data of 150 patients from Wuhan, China. Intensive Care Medicine [Internet]. 2020 May 1 [cited 2020 Oct 31];46(5):846-8. Available from: https:// doi.org/10.1007/s00134-020-05991-x.

7. Yazdanpanah N, Rezaei N. Autoimmune complications of COVID-19. Journal of Medical Virology [Internet]. 2021 Aug 31 [cited 2021 Sep 29]; Available from: https://onlinelibrary.wiley.com/doi/full/10.1002/ jmv.27292.

8. Obando-Pereda G. Can molecular mimicry explain the cytokine storm of SARS-CoV-2?: An in silico approach. Journal of Medical Virology [Internet]. 2021 Sep 1 [cited 2021 Sep 29];93(9):5350-7. Available from: https://onlinelibrary.wiley.com/doi/ full/10.1002/jmv. 27040 .

9. Mortaz E, Tabarsi P, Varahram M, Folkerts G, Adcock IM. The Immune Response and Immunopathology of COVID-19. Frontiers in Immunology [Internet]. 2020 Aug 26 [cited 2020 Oct 27];11:2037. Available from: www.frontiersin.org

10. Xiao F, Han M, Zhu X, Tang $Y$, Huang E, Zou H, et al. The immune dysregulations in COVID-19: implications for the management of rheumatic diseases. Modern rheumatology [Internet]. 2021 Jan 11;111. Available from: http://www.ncbi.nlm.nih.gov/ pubmed/33427554.

11. Wen W, Su W, Tang H, Le W, Zhang $X$, Zheng $Y$, et al. Immune cell profiling of COVID-19 patients in the recovery stage by single-cell sequencing. Cell discovery [Internet]. 2020 May 4 [cited 2020 May 17];6(1):31. Available from: http://www.ncbi.nlm.nih. gov/pubmed/32377375.
12. Hoepel W, Chen H-J, Allahverdiyeva S, Manz X, Aman $J$, Bonta $\mathrm{P}$, et al. Anti-SARS-CoV-2 IgG from severely ill COVID-19 patients promotes macrophage hyper-inflammatory responses. 2020;

13. Liao M, Liu Y, Yuan J, Wen Y, Xu G, Zhao J, et al. Single-cell landscape of bronchoalveolar immune cells in patients with COVID-19. Nature Medicine [Internet]. 2020 Jun 1 [cited 2021 Jan 31];26(6):842-4. Available from: https://doi.org/10.1038/s41591-0200901-9.

14. Zhang YY, Li BR, Ning BT. The Comparative Immunological Characteristics of SARS-CoV, MERS-CoV, and SARS-CoV-2 Coronavirus Infections. Frontiers in Immunology [Internet]. 2020 Aug 14 [cited 2021 Jan 27];11:2033. Available from: www.frontiersin.org.

15. Long Q-X, Tang X-J, Shi Q-L, Li Q, Deng H-J, Yuan $J$, et al. Clinical and immunological assessment of asymptomatic SARS-CoV-2 infections. Nature Medicine [Internet]. 2020 Jun 18 [cited 2020 Jul 6];1-5. Available from: http://www.nature.com/articles/ s41591-020-0965-6.

16. Lin L, Lu L, Cao W, Li T. Hypothesis for potential pathogenesis of SARS-CoV-2 infection-a review of immune changes in patients with viral pneumonia. Emerging Microbes \& Infections [Internet]. 2020 Jan 1 [cited 2020 Apr 5];9(1):727-32. Available from: https://www.tandfonline.com/doi/full/10.1080/2222 1751.2020.1746199.

17. Kaneko N, Kurata M, Yamamoto T, Morikawa S, Masumoto $\mathrm{J}$. The role of interleukin-1 in general pathology. Inflammation and Regeneration [Internet]. 2019 Jun 6 [cited 2020 Nov 15];39(1):1-16. Available from: https://doi.org/10.1186/s41232-019-0101-5.

18. IL1B interleukin 1 beta [Homo sapiens (human)] Gene - NCBI [Internet]. [cited 2020 Apr 6]. Available from: https://www.ncbi.nlm.nih.gov/gene?Db=gene \&Cmd=ShowDetailView\&TermToSearch $=3553$.

19. Murakami M, Kamimura D, Hirano T. Pleiotropy and Specificity: Insights from the Interleukin 6 Family of Cytokines. Immunity. 2019 Apr 16;50(4):812-31..

20. Aguilar JB, Gutierrez JB. Investigating the Impact of Asymptomatic Carriers on COVID-19 Transmission. medRxiv. 2020 Mar 31;2020.03.18.20037994..

21. Cañas CA. The triggering of post-COVID-19 autoimmunity phenomena could be associated with both transient immunosuppression and an inappropriate form of immune reconstitution in susceptible individuals. Medical Hypotheses [Internet]. 2020 Dec 1 [cited 2021 Jan 24];145:110345. Available from: /pmc/ articles/PMC7556280/?report=abstract.

22. Xiao $\mathrm{M}$, Zhang $\mathrm{Y}$, Zhang $\mathrm{S}$, Qin $\mathrm{X}$, Xia $\mathrm{P}$, Cao W, et al. Antiphospholipid Antibodies in Critically III Patients With COVID-19. Arthritis and Rheumatology. 2020 Dec 1;72(12):1998-2004..

23. Vojdani A, Kharrazian D. Potential antigenic cross-reactivity between SARS-CoV-2 and human tissue with a possible link to an increase in autoimmune diseases. Clinical Immunology. 2020 Aug 1;217:108480.

24. Bastard P, Gervais A, Voyer T le, Rosain J, Philippot Q, Manry J, et al. Autoantibodies neutralizing type I IFNs are present in $\sim 4 \%$ of uninfected individuals over 70 years old and account for $\sim 20 \%$ of COVID-19 deaths. 
Science Immunology [Internet]. 2021 Aug 19 [cited 2021 Sep 29];6(62). Available from: https://www.science.org/doi/abs/10.1126/sciimmunol.abl4340.

25. Bastard P, Rosen LB, Zhang Q, Michailidis E, Hoffmann $\mathrm{HH}$, Zhang $\mathrm{Y}$, et al. Autoantibodies against type I IFNs in patients with life-threatening COVID-19. Science [Internet]. 2020 Oct 23 [cited 2021 Sep 29];370(6515). Available from: https://doi. org/10.1126/science.abd4585.

26. Jones VG, Mills M, Suarez D, Hogan CA, Yeh D, Bradley Segal J, et al. COVID-19 and Kawasaki Disease: Novel Virus and Novel Case. Hospital pediatrics [Internet]. 2020 Apr 7 [cited 2021 Feb 1];10(6). Available from: https://pubmed.ncbi.nlm.nih.gov/32265235/.

27. Verdoni L, Mazza A, Gervasoni A, Martelli L, Ruggeri $M$, Ciuffreda $M$, et al. An outbreak of severe Kawasaki-like disease at the Italian epicentre of the SARS-CoV-2 epidemic: an observational cohort study. The Lancet [Internet]. 2020 Jun 6 [cited 2021 Feb 1];395(10239):1771-8. Available from: /pmc/articles/PMC7220177/?report=abstract.

28. Manganotti P, Pesavento V, Buoite Stella A, Bonzi L, Campagnolo E, Bellavita G, et al. Miller Fisher syndrome diagnosis and treatment in a patient with SARS-CoV-2. Journal of NeuroVirology [Internet]. 2020 Aug 1 [cited 2021 Feb 1];26(4):605-6. Available from: https://doi.org/10.1007/s13365-020-00858-9.

29. Zulfiqar A-A, Lorenzo-Villalba N, Hassler P, Andrès $E$. Immune Thrombocytopenic Purpura in a Patient with Covid-19. New England Journal of Medicine [Internet]. 2020 Apr 30 [cited 2021 Feb 1];382(18):e43. Available from: https://www.ncbi.nlm.nih.gov/pmc/ articles/PMC7179995/

30. Bonometti R, Sacchi MC, Stobbione P, Lauritano EC, Tamiazzo S, Marchegiani A, et al. The first case of systemic lupus erythematosus (SLE) triggered by COVID-19 infection. European Review for Medical and Pharmacological Sciences. 2020;24(18):9695-7.

31. Sedaghat Z, Karimi N. Guillain Barre syndrome associated with COVID-19 infection: A case report. Journal of Clinical Neuroscience [Internet]. 2020 Jun 1 [cited 2021 Feb 1];76:233-5. Available from: /pmc/ articles/PMC7158817/?report=abstract.

32. Giannini M, Ohana M, Nespola B, Zanframundo G, Geny B, Meyer A. Similarities between COVID-19 and anti-MDA5 syndrome: what can we learn for better care? European Respiratory Journal [Internet]. 2020 Jul 6 [cited 2021 Feb 1];56(3). Available from: https:// doi.org/10.1183/13993003.01618-2020.

33. Tsao HS, Chason HM, Fearon DM. Immune thrombocytopenia (ITP) in a pediatric patient positive for SARS-CoV-2. Pediatrics [Internet]. 2020 Aug 1 [cited 2021 Feb 1];146(2). Available from: https://doi. org/10.1542/peds.2020-1419.

34. Rubens JH, Akindele NP, Tschudy MM, Sick-Samuels AC. Acute covid-19 and multisystem inflammatory syndrome in children. BMJ [Internet]. 2021 Mar 1 [cited 2021 Sep 30];372. Available from: https://www. bmj.com/content/372/bmj.n385.

35. Rand ML, Wright JF. Virus-associated idiopathic thrombocytopenic purpura. Transfusion Science. 1998 Sep 1;19(3):253-9.
36. Kitamura $\mathrm{K}$, Ohta $\mathrm{H}$, Ihara $\mathrm{T}$, Kamiya $\mathrm{H}$, Ochiai $\mathrm{H}$, Yamanishi $\mathrm{K}$, et al. Idiopathic thrombocytopenic purpura after human herpesvirus 6 infection. The Lancet [Internet]. 1994 Sep 17 [cited 2021 Feb 1];344(8925):830. Available from: http://www.thelancet.com/article/S0140673694923906/fulltext.

37. Hamada M, Yasumoto S, Furue M. A Case of Varicella-Associated Idiopathic Thrombocytopenic Purpura in Adulthood. The Journal of Dermatology [Internet]. 2004 Jun 1 [cited 2021 Feb 1];31(6):477-9. Available from: http://doi.wiley.com/10.1111/j.1346-8138.2004. tb00536.x.

38. DiMaggio D, Anderson A, Bussel JB. Cytomegalovirus can make immune thrombocytopenic purpura refractory. British Journal of Haematology [Internet]. 2009 Jul 1 [cited 2021 Feb 1];146(1):104-12. Available from: http:// doi.wiley.com/10.1111/j.1365-2141.2009.07714.x.

39. Espinoza C, Kuhn C. Viral Infection of Megakaryocytes in Varicella with Purpura. American Journal of Clinical Pathology [Internet]. 1974 Feb 1 [cited 2021 Feb 1];61(2):203-8. Available from: https://academic.oup.com/ajcp/article-lookup/doi/10.1093/ ajcp/61.2.203.

40. Jawed M, Khalid A, Rubin M, Shafiq R, Cemalovic N. Acute Immune Thrombocytopenia (ITP) Following COVID-19 Vaccination in a Patient With Previously Stable ITP. Open Forum Infectious Diseases [Internet]. 2021 Jul 1 [cited 2021 Sep 29];8(7). Available from: https://academic.oup.com/ofid/article/8/7/ ofab343/6308965.

41. Zhao ZS, Granucci F, Yeh L, Schaffer PA, Cantor H. Molecular mimicry by herpes simplex virus-type 1: Autoimmune disease after viral infection. Science [Internet]. 1998 Feb 27 [cited 2021 May 11];279(5355):1344-7. Available from: https:// pubmed.ncbi.nlm.nih.gov/9478893/.

42. Cusick MF, Libbey JE, Fujinami RS. Molecular mimicry as a mechanism of autoimmune disease. Clinical Reviews in Allergy and Immunology [Internet]. 2012 Feb [cited 2021 May 11];42(1):102-11. Available from: /pmc/articles/PMC3266166/.

43. Cornaby C, Gibbons L, Mayhew V, Sloan CS, Welling A, Poole BD. B cell epitope spreading: Mechanisms and contribution to autoimmune diseases. Immunology Letters [Internet]. 2015 Jan 1 [cited 2021 May 11];163(1):56-68. Available from: https://pubmed. ncbi.nlm.nih.gov/25445494/.

44. Didona D, di Zenzo G. Humoral epitope spreading in autoimmune bullous diseases. Frontiers in Immunology [Internet]. 2018 Apr 17 [cited 2021 Feb 4];9(APR):1. Available from: www.frontiersin.org.

45. Powell AM, Black MM. Epitope spreading: protection from pathogens, but propagation of autoimmunity? Clinical and Experimental Dermatology [Internet]. 2001 Jul 1 [cited 2021 Feb 1];26(5):427-33. Available from: http://doi.wiley.com/10.1046/j.1365-2230 .2001.00852.x.

46. Vanderlugt $C L$, Miller SD. Epitope spreading in immune-mediated diseases: Implications for immunotherapy. Nature Reviews Immunology [Internet]. 2002 [cited 2021 Feb 4];2(2):85-95. Available from: https://www.nature.com/articles/nri724. 
47. Benoist C, Mathis D. Autoimmunity provoked by infection: How good is the case for $\mathrm{T}$ cell epitope mimicry? Vol. 2, Nature Immunology. 2001. p. 797$801 .$.

48. Ponomarenko J, Bui HH, Li W, Fusseder N, Bourne $P E$, Sette $A$, et al. ElliPro: $A$ new structure-based tool for the prediction of antibody epitopes. BMC Bioinformatics [Internet]. 2008 Dec 2 [cited 2021 May 24];9:514. Available from: /pmc/articles/ PMC2607291/.

49. Nielsen $M$, Lundegaard $C$, Lund $O$. Prediction of MHC class II binding affinity using SMM-align, a novel stabilization matrix alignment method. BMC Bioinformatics [Internet]. 2007 Apr 4 [cited 2021 May 24];8:238. Available from: /pmc/articles/ PMC1939856/.

50. Laskowski RA, Swindells MB. LigPlot+: Multiple ligand-protein interaction diagrams for drug discovery. Journal of Chemical Information and Modeling [Internet]. 2011 Oct 24 [cited 2021 May 24];51(10):277886. Available from: https://pubmed.ncbi.nlm.nih. gov/21919503/.

51. Lee H, Heo L, Lee MS, Seok C. GalaxyPepDock: A protein-peptide docking tool based on interaction similarity and energy optimization. Nucleic Acids Research [Internet]. 2015 [cited 2021 May 24];43(W1):W431-5. Available from: https://pubmed. ncbi.nlm.nih.gov/25969449/.

52. Kerlan-Candon S, Combe B, Vincent R, Clot J, Pinet V, Eliaou JF. HLA-DRB1 gene transcripts in rheumatoid arthritis. Clinical and Experimental Immunology [Internet]. 2001 [cited 2021 Mar 15];124(1):142-9. Available from: /pmc/articles/PMC1906025/.

53. Arango MT, Perricone C, Kivity S, Cipriano E, Ceccarelli $F$, Valesini G, et al. HLA-DRB1 the notorious gene in the mosaic of autoimmunity. Immunologic Research [Internet]. 2017 Feb 1 [cited 2021 Mar 22];65(1):82-98. Available from: https://link.springer.com/article/10.1007/s12026-016-8817-7.

54. Simmonds M, Gough S. The HLA Region and Autoimmune Disease: Associations and Mechanisms of Action. Current Genomics [Internet]. 2009 Feb 14 [cited 2021 Mar 22];8(7):453-65. Available from: /pmc/ articles/PMC2647156/.

55. Shimane K, Kochi Y, Suzuki A, Okada Y, Ishii T, Horita $T$, et al. An association analysis of HLA-DRB1 with systemic lupus erythematosus and rheumatoid arthritis in a Japanese population: Effects of $*$ 09:01 allele on disease phenotypes. Rheumatology (United Kingdom) [Internet]. $2013 \mathrm{Jul}$ [cited $2021 \mathrm{Mar}$ 15];52(7):1172-82. Available from: https://pubmed. ncbi.nlm.nih.gov/23407388/.

56. Sinha S, Prasad KN, Jain D, Nyati KK, Pradhan S, Agrawal S. Immunoglobulin IgG Fc-receptor polymorphisms and HLA class II molecules in Guillain-Barré syndrome. Acta Neurologica Scandinavica [Internet]. 2010 Jan 25 [cited 2021 Mar 15];122(1):21-6. Available from: http://doi.wiley.com/10.1111/j.1600-0404 .2009.01229.x.

57. Fekih-Mrissa N, Mrad M, Riahi A, Sayeh A, Zaouali J, Gritli N, et al. Association of HLA-DR/DQ polymorphisms with Guillain-Barré syndrome in Tunisian patients. Clinical Neurology and Neurosurgery [Internet]. 2014 [cited 2021 Mar 15];121:19-22. Available from: https://pubmed.ncbi.nlm.nih.gov/24793468/.

58. Hasan ZN, Zalzala HH, Mohammedsalih HR, Mahdi BM, Abid LA, Shakir ZN, et al. Association between human leukocyte antigen-DR and demylinating guillain-barré syndrome. Neurosciences [Internet]. 2014 [cited 2021 Mar 15];19(4):301-5. Available from: www. neurosciencesjournal.org.

59. Nielsen M, Lund O, Buus S, Lundegaard C. MHC Class II epitope predictive algorithms. Immunology [Internet]. 2010 Jul [cited 2021 Apr 11];130(3):319-28. Available from: /pmc/articles/PMC2913211/.

60. Nielsen M, Lundegaard C, Lund O. Prediction of MHC class II binding affinity using SMM-align, a novel stabilization matrix alignment method. BMC Bioinformatics [Internet]. 2007 Apr 4 [cited 2021 Apr 12];8:238. Available from: /pmc/articles/PMC1939856/.

61. Danke NA, Koelle DM, Yee C, Beheray S, Kwok WW. Autoreactive T Cells in Healthy Individuals. The Journal of Immunology [Internet]. 2004 May 15 [cited 2021 May 14];172(10):5967-72. Available from: http://www. jimmunol.org/content/172/10/5967http://www.jimmunol.org/content/172/10/5967.full\#ref-list-1.

62. Yan J, Mamula MJ. Autoreactive T Cells Revealed in the Normal Repertoire: Escape from Negative Selection and Peripheral Tolerance. The Journal of Immunology [Internet]. 2002 Apr 1 [cited 2021 May 11];168(7):3188-94. Available from: http://www.jimmunol.org/content/168/7/3188http://www.jimmunol.org/content/168/7/3188. full\#ref-list-1.

63. McMahon EJ, Bailey SL, Castenada CV, Waldner $\mathrm{H}$, Miller SD. Epitope spreading initiates in the CNS in two mouse models of multiple sclerosis. Nature Medicine [Internet]. 2005 Mar 27 [cited 2021 May 11];11(3):335-9. Available from: https://www.nature. com/articles/nm1202.

64. Vanderlugt CL, Miller SD. Epitope spreading in immune-mediated diseases: Implications for immunotherapy. Nature Reviews Immunology [Internet]. 2002 [cited 2021 May 11];2(2):85-95. Available from: https://www.nature.com/articles/nri724.

65. Angileri F, Legare S, Marino Gammazza A, Conway de Macario E, JL Macario A, Cappello F. Molecular mimicry may explain multi-organ damage in COVID-19. Autoimmunity Reviews [Internet]. 2020 Aug 1 [cited 2021 Apr 12];19(8):102591. Available from: /pmc/articles/PMC7289093/.

66. Olson JK, Croxford JL, Calenoff MiriamA, Dal Canto MC, Miller SD. A virus-induced molecular mimicry model of multiple sclerosis. Journal of Clinical Investigation [Internet]. 2001 Jul 15 [cited 2021 Feb 4];108(2):311-8. Available from: /pmc/articles/ PMC203030/?report=abstract.

67. Fujinami RS, von Herrath MG, Christen U, Whitton JL. Molecular mimicry, bystander activation, or viral persistence: Infections and autoimmune disease. Clinical Microbiology Reviews [Internet]. 2006 Jan 1 [cited 2021 Feb 4];19(1):80-94. Available from: http:// cmr.asm.org/.

68. Smatti MK, Cyprian FS, Nasrallah GK, al Thani AA, Almishal RO, Yassine HM. Viruses and Autoimmuni- 
ty: A Review on the Potential Interaction and Molecular Mechanisms. Viruses [Internet]. 2019 Aug 19 [cited 2021 Jan 27];11(8):762. Available from: https:// www.mdpi.com/1999-4915/11/8/762.

69. Farris AD, Keech CL, Gordon TP, McCluskey J. Epitope mimics and determinant spreading: Pathways to autoimmunity. Cellular and Molecular Life Sciences [Internet]. 2000 [cited 2021 May 14];57(4):56978. Available from: https://pubmed.ncbi.nlm.nih. gov/11130457/.

70. James JA, Harley JB. B-cell epitope spreading in autoimmunity. Immunological Reviews [Internet]. 1998 Aug 1 [cited 2021 May 11];164(1):185-200. Available from: https://onlinelibrary.wiley.com/doi/ full/10.1111/j.1600-065X.1998.tb01220.x.

71. Romagnani S. Immunological tolerance and autoimmunity. Internal and Emergency Medicine [Internet]. 2006 Sep [cited 2021 May 9];1(3):187-96. Available from: https://pubmed.ncbi.nlm.nih.gov/17120464/.

72. Wucherpfennig KW, Sethi D. T cell receptor recognition of self and foreign antigens in the induction of autoimmunity. Seminars in Immunology [Internet]. 2011 Apr [cited 2021 May 8];23(2):84-91. Available from: /pmc/articles/PMC3073734/.

73. Dardalhon V, Korn T, Kuchroo VK, Anderson AC. Role of Th1 and Th17 cells in organ-specific autoimmunity. Journal of Autoimmunity [Internet]. 2008 Nov [cited 2021 May 19];31(3):252-6. Available from: /pmc/ articles/PMC3178062/.

74. Gaylo A, Schrock DC, Fernandes NRJ, Fowell DJ. $T$ cell interstitial migration: Motility cues from the inflamed tissue for micro- and macro-positioning. Frontiers in Immunology [Internet]. 2016 Oct 14 [cited 2021 May 19];7(OCT). Available from: /pmc/articles/ PMC5063845/.

75. Guerriero JL. Macrophages: Their Untold Story in T Cell Activation and Function. International Review of Cell and Molecular Biology [Internet]. 2019 Jan 1 [cited 2021 May 19];342:73-93. Available from: https:// pubmed.ncbi.nlm.nih.gov/30635094/.

76. Martin B, Auffray C, Delpoux A, Pommier A, Durand $A$, Charvet $C$, et al. Highly self-reactive naive CD4 $T$ cells are prone to differentiate into regulatory $\mathrm{T}$ cells.
Nature Communications [Internet]. 2013 Jul 31 [cited 2021 May 11];4(1):1-12. Available from: www.nature. com/naturecommunications.

77. Sewell AK. Why must $T$ cells be cross-reactive? Nature Reviews Immunology [Internet]. 2012 Sep 24 [cited 2020 Nov 29];12(9):669-77. Available from: www.nature.com/reviews/immunol.

78. Gunzer M, Weishaupt C, Hillmer A, Basoglu Y, Friedl $P_{,}$ Dittmar KE, et al. A spectrum of biophysical interaction modes between T cells and different antigen-presenting cells during priming in 3-D collagen and in vivo. Blood [Internet]. 2004 Nov 1 [cited 2021 May 19];104(9):2801-9. Available from: http://ashpublications.org/blood/article-pdf/104/9/2801/1702797/ zh802104002801.pdf.

79. Meidaninikjeh S, Sabouni N, Marzouni HZ, Bengar S, Khalili A, Jafari R. Monocytes and macrophages in COVID-19: Friends and foes. Life Sciences [Internet]. 2021 Mar 15 [cited 2021 May 20];269:119010. Available from: /pmc/articles/PMC7834345/.

80. Alrubayyi A. NK cells in COVID-19: protectors or opponents? Nature Reviews Immunology [Internet]. 2020 Sep 1 [cited 2021 May 20];20(9):520. Available from: https://www.nature.com/articles/s41577-0200408-0.

81. Herrath MG, Fujinami RS, Whitton JL. Microorganisms and autoimmunity: Making the barren field fertile? Nature Reviews Microbiology [Internet]. 2003 [cited 2021 May 24];1(2):151-7. Available from: https://www.nature.com/articles/nrmicro754.

82. Cao X. COVID-19: immunopathology and its implications for therapy. Vol. 20, Nature Reviews Immunology. Nature Research; 2020. p. 269-70..

83. Chiappelli F. CoViD-19 Immunopathology \& Immunotherapy. Bioinformation [Internet]. 2020 Mar 31 [cited 2020 Nov 6];16(3):219-22. Available from: /pmc/articles/PMC7147500/?report=abstract

84. Favalli EG, Ingegnoli F, de Lucia O, Cincinelli G, Cimaz R, Caporali R. COVID-19 infection and rheumatoid arthritis: Faraway, so close! Autoimmunity Reviews [Internet]. 2020 May 1 [cited 2021 Jan 31];19(5):102523. Available from: /pmc/articles/ PMC7102591/?report=abstract. 